\title{
Will we reach the Sustainable Development Goals target for tuberculosis in the European Union/European Economic Area by 2030?
}

Hanna Merk ${ }^{1}$, Csaba Ködmön ${ }^{1}$, Marieke J van der Werf ${ }^{1}$

1. European Centre for Disease Prevention and Control (ECDC), Stockholm, Sweden

Correspondence: Hanna Merk (hanna.merk@ecdc.europa.eu)

Citation style for this article:

Merk Hanna, Ködmön Csaba, van der Werf Marieke J. Will we reach the Sustainable Development Goals target for tuberculosis in the European Union/European Economic Area by 2030?. Euro Surveill. 2019;24(12):pii=1900153. https://doi.org/10.2807/1560-7917.ES.2019.24.12.1900153

We assessed progress towards the Sustainable Development Goals target for tuberculosis in the European Union/European Economic Area using the latest tuberculosis (TB) surveillance and Eurostat data. Both the TB notification rate and the number of TB deaths were decreasing before 2015 and the TB notification rate further declined between 2015 and 2017 . With the current average decline in notification rate and number of TB deaths however, the EU/EEA will not reach the targets by 2030.

In 2015, all United Nations Member States adopted the 17 Sustainable Development Goals (SDGs) and their 169 targets [1]. The target for tuberculosis (TB) is to end the epidemic by 2030. The End TB Strategy provides three additional sub-targets that are used to measure progress towards the SDGs [2]. According to these sub-targets, the TB incidence should be $80 \%$ lower in 2030 compared with 2015; the number of TB deaths should be $90 \%$ lower and no family should face catastrophic costs due to TB. Here, we assess progress towards the first two sub-targets at European Union/ European Economic Area (EU/EEA) level. Information on catastrophic costs is not available at EU/EEA level.

\section{Analysis}

We used data obtained from the European tuberculosis surveillance network under the joint coordination of the European Centre for Disease Prevention and Control (ECDC) and World Health Organization (WHO) Regional Office for Europe [3] and data from Eurostat [4] for the years 2008-17. The TB case data were extracted from The European surveillance system (TESSy) [5] hosted by ECDC (as at 5 October 2018). Since Croatia did not report case-based TB data to TESSy for 2008-11, Croatia was excluded from the notification rate for those years. The population denominators for the notification rates were obtained from Eurostat (as at 20 April 2018), as were the data on cause of death due to TB (ICD 10 code A15-A19 and B9o, as at 21 November
2018) [6]. Cause of death data were only available up to 2015 (last updated by EUROSTAT on 20 July 2018). The TB notification rates were used as proxy for TB incidence and reported TB deaths as a proxy for actual number of deaths due to TB.

Countries with missing annual data on deaths and reporting 10 or less deaths per year in the remaining years were considered to have zero TB deaths for the years with missing data. Denmark did not report any data on TB deaths in 2010 but reported more than 10 deaths in the other years. We therefore estimated the number of TB deaths, by calculating the average of the two preceding and following years and applying the ceiling function in STATA version 14.2 (StataCorp, College Station, Texas, United States).

To assess whether the EU/EEA will reach the SDG target we used the average annual change in notification rate between 2008 and 2017 and the average annual change in number of deaths between 2008 and 2015 and assumed that the change will continue similarly in future.

For our analysis, we used STATA/SE 14.2.

\section{Key findings}

The total TB notification rate declined during the study period (Figure 1). In 2017, the notification rate was 10.7 per 100,000 population in the EU/EEA, resulting in an overall decline of $10 \%$ since 2015 . The average annual decline between 2008 and 2017 was $4.8 \%$.

An $80 \%$ reduction in TB notifications in the EU/EEA in 2030 compared with 2015 results in a target TB notification rate of 2.4 per 100,000 population.

If the $4.8 \%$ average annual decline continued unchanged, the EU/EEA would reach a TB notification 


\section{FIGURE 1}

Tuberculosis notification rate over time and the End TB Strategy 2030 sub-target for Sustainable Development Goal 3, European Union/European Economic Area, 2008-2030

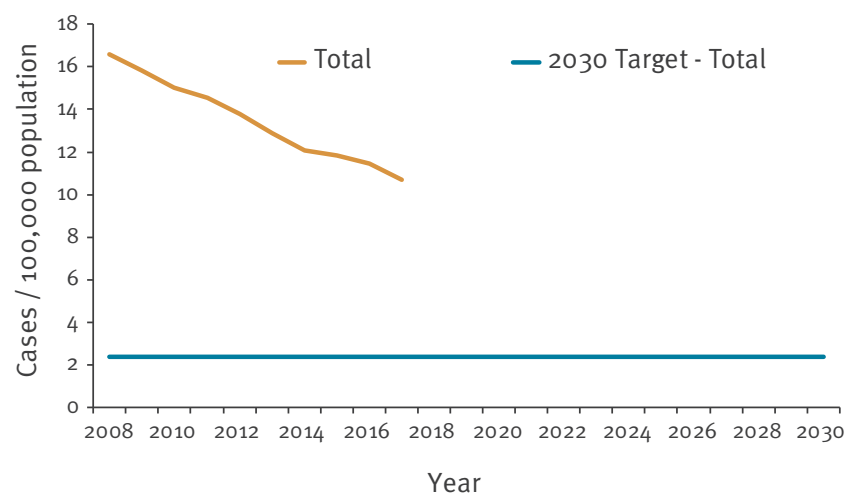

Blue line: $80 \%$ reduction in tuberculosis notification rate compared with 2015.

rate of 5.7 per 100,000 population in 2030 . The annual average decline required to reach the target is $10.9 \%$.

The total number of TB deaths declined during the study period (Figure 2). In 2015, the number of registered TB deaths was 4,437. Progress since 2015 cannot be measured as there is no available data after 2015 at EU/EEA level. The average annual decline between 2008 and 2015 was $5.3 \%$.

A 90\% reduction in TB deaths in the EU/EEA in 2030 compared with 2015 results in a target of 444 TB deaths per year.

If the $5.3 \%$ average annual decline continued unchanged, the EU/EEA would reach 1,947 TB deaths per year in 2030 . The annual average decline required to reach the target is $14.2 \%$.

\section{Discussion}

The targets for TB incidence and the number of TB deaths set in the End TB Strategy translate to 2.4 TB cases per 100,000 population and 444 TB deaths for the EU/EEA in 2030. Both the annual TB notification rate and the number of TB deaths were decreasing before 2015 and the TB notification rate further declined by $10 \%$ between 2015 and 2017. If the average $4.8 \%$ annual decline of the TB notification rate continues in the EU/EEA we will not reach the target by 2030 ; the average $5.3 \%$ decline of TB deaths is also not sufficient to reach the target.

Compared to other parts of the world, the observed TB notification rate and number of TB deaths in the EU/EEA are low [7]. Nonetheless, the SDG and End TB Strategy targets apply to the EU/EEA and our results show that there is little room for complacency.

\section{FIGURE 2}

Number of deaths due to tuberculosis over time and the End TB Strategy 2030 sub-target for Sustainable Development Goal 3, European Union/European Economic Area, 2008-2030

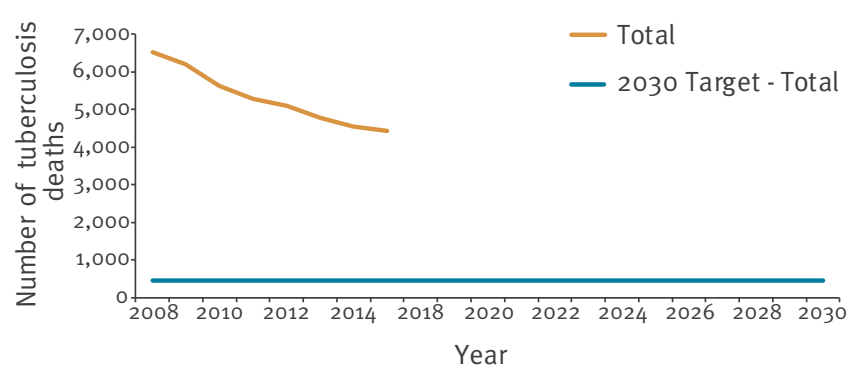

Blue line: $90 \%$ reduction in the number of tuberculosis deaths compared with 2015.

Globally, the average annual decline of the TB incidence rate was $1.5 \%$ between 2000 and 2017, far less than what was observed in the EU/EEA [7]. The global number of TB deaths among HIV-negative people decreased by $5 \%$ since 2015 and by $29 \%$ between 2000 and 2017 [7]. Since $33 \%$ of the reported TB cases in the EU/EEA are diagnosed in individuals of foreign origin [8], a decrease in the global incidence of TB may impact the observed TB incidence in the EU/EEA. This would be more apparent in countries that diagnose a large proportion of their TB cases in individuals of foreign origin such as Malta, Norway and Sweden (> $85 \%$ of TB cases of foreign origin).

Within the EU/EEA, some countries are closer to ending TB than others: 24 countries reported a notification rate ofless than 10 TB cases per 100,000 population [8]. In addition, there are substantial differences in the annual change in the TB notification rate in the EU/EEA [8]. In the period 2013-17, two countries observed an increasing notification rate of more than $5 \%$ per year, 17 had a decreasing notification rate of more than $5 \%$ and in 11 , the annual change was between - $5 \%$ and $+5 \%$. To reach the target of 2.4 TB cases per 100,000 population, different strategies may need to be applied within the EU/EEA countries, depending on the respective epidemiological situation. Similarly, the estimated TB deaths among HIV-negative persons in EU/EEA countries in 2017 ranged between zero and 920, with an annual percentage change ranging from $-17.6 \%$ to $15.0 \%$ between 2013 and 2017 [8]. Thus further indicating that some EU/EEA countries are making more progress towards the target than others are.

The End TB Strategy includes a package of interventions that are encouraged for use by countries to prevent and control TB and reach the targets [2]. The interventions are grouped under three pillars: (i) integrated, patient-centred care and prevention, (ii) bold policies and supportive systems, and (iii) intensified 
research and innovation. Countries are encouraged to adapt their strategy to the specifics of their TB epidemic. In 2017, 17 EU/EEA countries had a national TB control plan or strategy [9].

It is acknowledged that specific actions are needed in countries that are close to ending TB and aiming for TB elimination [10]. These countries will often have epidemics concentrated in hard-to-reach and vulnerable populations e.g. migrants, prisoners and homeless people. Targeting hard-to-reach and vulnerable populations requires specific interventions and may need additional resources [11-14]. For example, screening and providing treatment for latent TB infection (LTBI) prevents new TB cases $[15,16]$, as well as screening and treating prisoners and migrants for active TB may also contribute to a further decline $[12,13]$. To our knowledge, however, not all EU/EEA countries test hard-toreach populations for LTBI. Mathematical modelling and cost-effectiveness studies show that programmatic management of LTBI can have an impact on TB burden $[17,18]$. In addition, migrants are not screened for TB in all EU/EEA countries [19]. The interventions suggested in the ECDC guidance on TB control in vulnerable and hard to reach populations are also not implemented in all countries in the EU/EEA [11].

Our results come with limitations. We used notification rate as a proxy for TB incidence. We believe this to be a valid approach since several studies have shown that completeness of TB surveillance data in EU/EEA countries is $>80 \%$ [20-22]. We relied on the completeness and accuracy of the cause of death register for the number of TB deaths. The quality of death registration systems has been assessed as good in most countries of the WHO European Region [23]. We therefore consider our results valid for assessing progress towards the targets on an EU/EEA level. However, accurately assigning cause of death is challenging [24] and improvements in cause of death registration may still be needed on country level [25]. We recognise that improvements in both TB surveillance and cause of death registration can affect the progress assessment if more complete data become available.

In conclusion, additional interventions need to be implemented to reach the targets for TB incidence and number of TB deaths in the EU/EEA, and thus the SDG, especially in countries that are currently facing stable or increasing trends.

\section{Conflict of interest}

None declared.

\section{Authors' contributions}

CK, HM and MvdW all contributed to the study plan, writing, reviewing and revising of the manuscript and approved the final draft. CK and HM conducted the analysis.
References

1. United Nations (UN). Resolution adopted by the General Assembly on 25 September 2015. 70/1. Transforming our world: the 2030 Agenda for Sustainable Development. A/RES/70/1. New York: UN; 2015. Available from: http://www.un.org/en/ development/desa/population/migration/generalassembly/ docs/globalcompact/A_RES_70_1_E.pdf

2. World Health Organization (WHO). The end TB strategy. Geneva: WHO; 2014. Available from: https://www.who.int/tb/ strategy/End_TB_Strategy.pdf

3. European Centre for Disease prevention and Control (ECDC). European Tuberculosis Surveillance Network. Stockholm: ECDC. [Accessed: 14 Mar 2019]. Available from: https:// ecdc.europa.eu/en/about-uswho-we-workdisease-andlaboratory-networkstuberculosis-disease-network/ european

4. European Commission (EC). Eurostat. Your key to European statistics. [Accessed: 14 Mar 2019]. Available from: https:// ec.europa.eu/eurostat

5. European Centre for Disease prevention and Control (ECDC). ECDC activities on surveillance. Stockholm: ECDC. [Accessed: 14 Mar 2019]. Available from: https://ecdc.europa.eu/en/ about-uswhat-we-do/ecdc-activities-surveillance

6. Eurostat. Databases: hlth cd aro (2011-2015), hlth cd anr (1994-2010). Eurostat. [Accessed: 21 Nov 2018]. Available from: https://ec.europa.eu/eurostat/data/database

7. World Health Organization (WHO). Global tuberculosis report 2018. Geneva: WHO; 2018. Available from: https://www.who. int/tb/publications/global_report/en

8. European Centre for Disease Prevention and Control (ECDC)/ WHO Regional Office for Europe (WHO/Europe). Tuberculosis surveillance and monitoring in Europe 2019-2017 data. Stockholm/Copenhagen: ECDC/WHO/Europe; 2019. Available from: https://ecdc.europa.eu/sites/portal/files/documents/ tuberculosis-surveillance-monitoring-Europe-2019-18 Mar_2019.pdf

9. Collin SM, de Vries G, Lönnroth K, Migliori GB, Abubakar I, Anderson SR, et al. Tuberculosis in the European Union and European Economic Area: a survey of national tuberculosis programmes. Eur Respir J. 2018;52(6):1801449. https://doi. org/10.1183/13993003.01449-2018 PMID: 30309977

10. Lönnroth K, Migliori GB, Abubakar I, D’Ambrosio L, de Vries G, Diel R, et al. Towards tuberculosis elimination: an action framework for low-incidence countries. Eur Respir J. 2015;45(4):928-52. https://doi. org/10.1183/09031936.00214014 PMID: 25792630

11. European Centre for Disease Prevention and Control (ECDC). Guidance on tuberculosis control in vulnerable and hard-toreach populations. Stockholm: ECDC; 2016. Available from: https://ecdc.europa.eu/en/publications-data/public-healthguidance-tuberculosis-control-vulnerable-and-hard-reachpopulations

12. European Centre for Disease Prevention and Control (ECDC)/ European Monitoring Centre for Drugs and Drug Addiction (EMCDDA). Public health guidance on active case finding of communicable diseases in prison settings. Stockholm/Lisbon: ECDC/EMCDDA; 2018. Available from: https://ecdc.europa. eu/en/publications-data/public-health-guidance-active-casefinding-communicable-diseases-prison-settings

13. European Centre for Disease Prevention and Control (ECDC). Public health guidance on screening and vaccination for infectious diseases in newly arrived migrants within the EU/ EEA. Stockholm: ECDC; 2018. Available from: https://ecdc. europa.eu/en/publications-data/public-health-guidancescreening-and-vaccination-infectious-diseases-newly

14. Heuvelings CC, de Vries SG, Greve PF, Visser BJ, Bélard S, Janssen S, et al. Effectiveness of interventions for diagnosis and treatment of tuberculosis in hard-to-reach populations in countries of low and medium tuberculosis incidence: a systematic review. Lancet Infect Dis. 2017;17(5):e14458. https://doi.org/10.1016/S1473-3099(16)30532-1 PMID: 28291722

15. European Centre for Disease Prevention and Control (ECDC). Programmatic management of latent tuberculosis infection in the European Union. Stockholm: ECDC; 2018. Available from: https://ecdc.europa.eu/en/publications-data/programmaticmanagement-latent-tuberculosis-infection-european-union

16. World Health Organization (WHO). Latent tuberculosis infection: updated and consolidated guidelines for programmatic management. Geneva: WHO; 2018. Available from: https://www.who.int/tb/publications/2018/ latent-tuberculosis-infection/en

17. European Centre for Disease Prevention and Control (ECDC). Mathematical modelling of programmatic screening strategies for latent tuberculosis infection in countries with low tuberculosis incidence. Stockholm: ECDC; 2018. Available 
from: https://ecdc.europa.eu/sites/portal/files/documents/ Technical-Report_LTBI_math_modelling.pdf

18. European Centre for Disease Prevention and Control (ECDC). Cost-effectiveness analysis of programmatic screening strategies for latent tuberculosis infection in the EU/EEA. Stockholm: ECDC; 2018. Available from: https://ecdc. europa.eu/sites/portal/files/documents/LTBI\%20cost effectiveness\%2oreport.pdf

19. Dara M, Solovic I, Sotgiu G, D’Ambrosio L, Centis R, Tran R, et al. Tuberculosis care among refugees arriving in Europe: a ERS WHO Europe Region survey of current practices. Eur Respir J. 2016;48(3):808-17. https://doi.org/10.1183/13993003.008402016 PMID: 27492827

20. Cojocaru C, van Hest NA, Mihaescu T, Davies PD. Completeness of notification of adult tuberculosis in Iasi County, Romania: a capture-recapture analysis. Int J Tuberc Lung Dis. 2009;13(9):1094-9. PMID: 19723397

21. van Hest NA, Story A, Grant AD, Antoine D, Crofts JP, Watson JM. Record-linkage and capture-recapture analysis to estimate the incidence and completeness of reporting of tuberculosis in England 1999-2002. Epidemiol Infect. 2008;136(12):1606 16. https://doi.org/10.1017/So950268808000496 PMID: 18346285

22. van Hest NA, Smit F, Baars HW, De Vries G, De Haas PE, Westenend PJ, et al. Completeness of notification of tuberculosis in The Netherlands: how reliable is recordlinkage and capture-recapture analysis? Epidemiol Infect. 2007;135(6):1021-9. https://doi.org/10.1017/ So950268806007540 PMID: 17156496

23. van der Werf MJ, Borgdorff MW. Targets for tuberculosis control: how confident can we be about the data? Bull World Health Organ. 2007;85(5):370-6. https://doi.org/10.2471/ BLT.06.039941 PMID: 17639222

24. Wexelman BA, Eden E, Rose KM. Survey of New York City resident physicians on cause-of-death reporting, 2010. Prev Chronic Dis. 2013;10:E76. https://doi.org/10.5888/ pcd10.120288 PMID: 23660118

25. Lalor MK, Mohiyuddin T, Uddin T, Thomas HL, Lipman M, Campbell CNJ. The challenge of estimating tuberculosis mortality accurately in England and Wales. Int J Tuberc Lung Dis. 2018;22(5):572-8. https://doi.org/10.5588/ijtld.17.0695 PMID: 29663964

\section{License, supplementary material and copyright}

This is an open-access article distributed under the terms of the Creative Commons Attribution (CC BY 4.0) Licence. You may share and adapt the material, but must give appropriate credit to the source, provide a link to the licence and indicate if changes were made.

Any supplementary material referenced in the article can be found in the online version.

This article is copyright of the authors or their affiliated institutions, 2019. 